\title{
Measuring the Technical Efficiency of Municipal Water Suppliers: the Role of Environmental Factors
}

Steven Renzetti ${ }^{\mathrm{i}}$ and Diane Dupont ${ }^{\mathrm{ii}}$

\author{
July, 2008
}




\begin{abstract}
This paper extends the multistage procedure set out in Fried et al (1999) to examine the importance of environmental factors when assessing the technical efficiency of water agencies. However, following Simar and Wilson's (2007) critique of multistage efficiency analyses, the paper uses a bootstrapping approach in order to have consistent inference. Data are from a cross-section of municipal water agencies in Ontario, Canada during 1996. The main findings are that environmental factors explain some of the observed variation in efficiency scores and that water agencies' relative efficiency scores are changed substantially after controlling for environmental factors.
\end{abstract}




\section{INTRODUCTION}

Concerns regarding deteriorating infrastructure, threats to drinking water quality and rising supply costs have generated a renewed interest in developing the capacity and analytic techniques to assess and measure water utility performance (Shirley, 2002). This type of performance review can play a role in decisions related to rate setting, allocation of investment funds and optimal scaling of agencies. This paper extends a three-stage procedure proposed by Fried et. al (1999) to rank and assess the relative technical efficiency of municipal water suppliers. The first stage employs Data Envelopment Analysis (Charnes, Cooper and Rhodes, 1978) to develop measures of the local water agencies' input slack scores and relative technical efficiency. The second stage employs truncated and Tobit regression analyses to explain the variation observed in agencies' first stage calculated input slack scores. An important feature of the second stage analysis is that it identifies the role of those factors influencing technical efficiency (and, hence, input slacks) that are not under the supplier's control such as: climate, the source of raw water and population density. Furthermore, following Simar and Wilson's (2007) critique of multistage efficiency assessments, the second stage employs a bootstrapping approach to obtain confidence intervals for the estimated coefficients. The third stage reruns the Data Envelopment Analysis (DEA) programming problem using inputs that have been adjusted to reflect differences in the nature of agencies' exogenous conditions. The output of the third stage is a set of relative efficiency rankings that corrects for exogenous differences in water agencies' operating environments. 
The data employed in this study are a 1996 cross sectional sample of municipal water suppliers operating in Ontario, Canada. Included in the data set are observations on water utility operations (output levels, input expenditures and distribution network length) as well as characteristics of the municipality in which the water supplier operates (elevation, source of raw water, temperature, precipitation and population density).

The stage 1 results indicate that there appear to be substantial variations in efficiency levels across Ontario's municipal water suppliers and that average technical efficiency levels are relatively low. The truncated and Tobit regressions of stage 2 reveal that several environmental factors have a significant influence over efficiency scores. Stage 3 shows that the relative scores of water supplier efficiency and input slacks from stage 1 are changed markedly by controlling for environmental factors outside of the agencies' control. Specifically, the mean technical efficiency score rises from 0.538 in the first stage to 0.604 and 0.822 (for the Tobit and truncated models respectively) in the third stage. Thus, this paper demonstrates that computing relative technical efficiency scores without adjusting for serial correlation in the second stage regression analysis and for differences in water agencies' external operating environments may yield misleading results.

\section{PAST RESEARCH}

A number of methods have been used to assess the performance of municipal water agencies. Renzetti and Dupont (2003) and Conti (2005) review and critically assess this literature. Both papers conclude that a variety of factors influence the technical efficiency 
of local water agencies. These include scale of operations, ownership, source of raw water, population density, financial and water quality regulations, the relative importance of non-residential vs. residential demand, and local topological conditions. Conti (2005) also concludes that "the survey of the literature has highlighted ...the role played by environmental variables in 'shaping' both the technology and the efficiency levels of the water utility industry.” (p. 297).

A number of authors have employed DEA methods to assess water agency efficiency. Early applications include Byrnes, Grosskopf and Hayes (1986) and Lambert, Dichev and Raffiee (1993). The Lambert study employed a cross-sectional sample of U.S. water utilities to examine the differences in efficiency achieved by private and publicly owned water utilities. Output was measured by the total quantity of wholesale and retail water delivered. Inputs included were annual labour use, total British thermal units of energy used, total value of material inputs used, and total book value of each agency's capital stock. The authors found that higher levels of technical and overall efficiency were obtained for publicly owned water utilities; however, only $16 \%$ of public agencies and $3 \%$ of privately owned utilities were fully technically efficient.

Shih et. al (2004) extended the previous analyses by carrying out a two-stage procedure that, first, implements a DEA of water agencies and, second, regresses the computed efficiency scores against a set of explanatory variables. The authors found evidence of economies of scale and wide variations in technical efficiency across observations. In the second stage, the authors regressed the computed technical efficiency 
scores on the size of water agency, source of raw water and ownership type. Scale of the water supplier was found to be positively correlated with technical efficiency. Again, public water agencies were found to be more technically efficient than privately owned suppliers. Anwandter L. and T. Ozuna (2002) carried out a similar two-stage analysis using observations from Mexican municipal water agencies.

Fried et al (1999) added one more stage to efficiency analysis by using information provided in the second stage regression to adjust inputs to reflect environmental factors that are outside the control of agency managers. These adjusted inputs were then used in a further DEA analysis that now incorporated these impacts. However, Simar and Wilson (2007) pointed out a potential shortcoming in any multistage assessments arising from the fact that DEA efficiency scores are not directly observed ${ }^{\mathrm{iii}}$. Instead they are empirically estimated from a sample of data, hence, the error terms in second-stage regressions that try to explain these scores are likely to be serially correlated "in a complicated, unknown way" (p.39). Clearly, this inhibits inference. In addition, the authors argued that researchers need to incorporate the implicit restrictions upon the domain of such scores in the estimation. Simar and Wilson's recommended solution was the use of a truncated regression in the second stage and the employment of a bootstrapping approach in order to improve on inference relating to the estimated coefficients. These suggestions are both adopted for this paper. 


\section{INSTITUTIONAL BACKGROUND}

The preceding section demonstrates the continuing interest on the part of researchers in water agency performance. Most governments have also demonstrated a growing degree of interest in water agency performance and conformity with environmental, financial and/or price-setting regulations. The degree of regulation of local water agencies, however, varies significantly across jurisdictions (Madhoo, 2007). Perhaps the most comprehensive regulatory environment is found in England and Wales where the privatization of water agencies under the Thatcher government was combined with extensive assessment of water agency performance and regulation of price setting. For the purpose of this paper, the most interesting feature of England's price regulation is the Office of Water's use of DEA and econometric models to assess the relative performance of water agencies (Thanassoulis, 2001).

In Canada, regulation of municipal water agencies is a provincial responsibility and, thus, varies across provinces. In Ontario, the province from which the data are drawn, regulation of local water agencies traditionally has been limited to the establishment of drinking water standards. There has been little or no oversight of agencies' debt levels, investments or pricing decisions. This lack of regulatory oversight has been identified as one of the factors leading to inefficient pricing and capacity decisions by Ontario water agencies (Renzetti, 1999).

There is evidence, however, of renewed interest in water agency performance in Ontario and other Canadian provinces. Recent Ontario legislation requires that water 
agencies move to full-cost accounting and full-cost pricing (Renzetti, 2007). Further, a recent report to the Ontario government recommends enhanced pricing regulation, consolidation of agencies serving small and remote communities and measurement of relative efficiency of agencies. The report specifically recommends that government require water agencies to report on their environmental, financial and pricing performance so that they may be compared to other agencies in the province. In its analysis of the costs of water supply, the report argues "A caution in assessing all studies that attempt to link system size and system costs is that they generally ignore the impact of other factors - population density, water source, terrain and climate, for example - on costs. This is a significant problem, because in Ontario these factors may well affect small places disproportionately.” (Water Strategy Expert Panel, 2005, p.84).

\section{METHOD AND DATA}

We employ the multistage procedure suggested by Fried et. al (1999) in order to measure and explain the relative efficiency of municipal water suppliers in Ontario, Canada. The key innovation in this approach is that it identifies and corrects for the influence of factors such as population density or source of raw water supplies which may influence the performance of these agencies but are outside of the control of water agency managers.

Assume that each of $k=1 \ldots \mathrm{K}$ municipal water agencies employs inputs $\mathrm{x}_{\mathrm{j}}^{\mathrm{k}}, \mathrm{j}=$ 1 ...J to produce a scalar measure of output $\mathrm{y}^{\mathrm{k}}$. Each agency's technical efficiency (TE) may be measured by the quantity of inputs required to produce a given level of output or 
the quantity of output achieved by a given vector of input quantities. For our analysis, it is necessary to assume that output is exogenous for Ontario water agencies as they are required by law to supply whatever quantity of water is demanded by their customers. As a result, we adopt an input-orientated DEA approach.

The first stage of the analysis involves the application of a variable returns to scale DEA procedure to the agencies' inputs and output (Coelli, Rao and Battese, 1999). This procedure yields radial technical efficiency measures for the $\mathrm{k}^{\text {th }}$ agency $\left(\mathrm{TE}^{\mathrm{k}}\right)$, scale economy estimates and non-radial input slack measures $\left(\theta_{\mathrm{j}}{ }^{\mathrm{k}}\right)$ for the $\mathrm{k}^{\text {th }}$ agency's use of the $\mathrm{j}^{\text {th }}$ input. The radial and non-radial slack measures can be defined with the aid of Figure 1. In the figure $\mathrm{x}_{1}$ and $\mathrm{x}_{2}$ are inputs that are employed to produce a specified level of output. Points A, B, C and $\mathrm{C}^{*}$ represent the input combinations used by four different firms. Points A, B and C* make-up an efficiency frontier. The radial measure of technical efficiency for firm $C\left(\mathrm{TE}^{\mathrm{C}}\right)$ is given by the ratio $0 \mathrm{C}^{*} / 0 \mathrm{C}$. Further, $\left(1-\mathrm{TE}^{\mathrm{C}}\right) \cdot \mathrm{x}^{\mathrm{C}}$ is the radial input slack for $\mathrm{x}_{1}{ }^{\mathrm{C}}$ and $\mathrm{x}_{2}{ }^{\mathrm{C}}$. It is important to see that $\mathrm{C}$ could decrease $\mathrm{x}_{2}$ even more by $\left(\mathrm{x}_{2}{ }^{\mathrm{C}}-\mathrm{x}_{2}{ }^{\mathrm{B}}\right)$ without decreasing output. Thus $\theta_{2}{ }^{\mathrm{c}}=\left(\mathrm{x}_{2}{ }^{\mathrm{C}^{*}}-\mathrm{x}_{2}{ }^{\mathrm{B}}\right)$ is the nonradial input slack for $\mathrm{x}_{2}{ }^{\mathrm{C}}$.

An important challenge facing someone looking at the output of a DEA model is how to assess differences in $\mathrm{TE}^{\mathrm{k}}$ and $\theta_{\mathrm{j}}^{\mathrm{k}}$ scores across observations. In particular, does a higher $\mathrm{TE}^{\mathrm{k}}$ and/or lower $\theta_{\mathrm{j}}^{\mathrm{k}}$ score always indicate 'better' performance? Some agency managers might argue that their efficiency scores and/or input slacks reflect the effects of factors outside of their control such as local climate, topological and population density 
conditions. For example, a municipal water agency located in a city that experienced a particularly cool and rainy summer would record a lower level of output than a similarly situated agency in a city that experienced a hot and dry summer. These differences in outputs may not be fully accounted for in differences in input use due to indivisibilities in capital stocks and long-term labour contracts. If factors such as climate do, in fact, play a role in determining agency relative efficiency and if they differ across agencies, then there should be some way of accounting for them when examining behaviour.

In order to examine the role of external factors upon water agencies, the second stage of our procedure regresses the total input slack values on a vector of variables that are expected to influence efficiency but are outside of the control of water agency managers. We begin by defining the total slack for each firm $\left(\alpha_{j}^{k}\right)$ in equation (1). This is the sum of the radial $\left(\left(1-\mathrm{TE}^{\mathrm{k}}\right) \cdot \mathrm{x}_{\mathrm{j}}{ }^{\mathrm{k}}\right)$ and non-radial $\left(\theta_{\mathrm{j}}{ }^{\mathrm{k}}\right)$ slacks for the $\mathrm{k}^{\text {th }}$ agency's $\mathrm{j}^{\text {th }}$ input.

(1) $\alpha_{j}^{k}=\left(1-T E^{k}\right) \cdot x_{j}^{k}+\theta_{j}^{k}$ for $j=1 \ldots J$ and $k=1 \ldots K$

We hypothesize that the impact of exogenous environmental factors on the $\alpha_{j}{ }^{k}$ values is shown in equation (2) where $z_{j}^{k}$ is a set of “ $j$ ” exogenous variables whose estimated coefficients are identified by the $\beta \mathrm{j}$. A positive coefficient indicates that the environmental variable raises the value of $\alpha_{j}^{k}$ and, thus, contributes to inefficiency while a negative coefficient may be interpreted in the opposite fashion. 
(2) $\alpha_{j}^{k}=f_{j}\left(z_{j}^{k}, \beta_{j}, e_{j}^{k}\right)$ for $j=1 \ldots J$

For estimation purposes equation (2) is typically (Fried et al 1999) assumed to be linear in the explanatory variables and its statistical noise term $\left(e_{j}^{k}\right)$ is assumed to be a normal random variable with mean of 0 and variance of $\sigma_{e^{k}}^{2}$. An empirical consideration arises from the manner in which the $\alpha_{j}{ }^{\mathrm{k}}$ are constructed, namely, a minimum slack of zero is observed for the most efficient operation. A typical response, as exemplified in Fried et al (1999), is to assume that the error term is distributed censored normal thereby requiring a Tobit procedure. These assumptions give rise to the traditional second stage approach. Recently, however, Simar and Wilson (2007) have identified three issues arising from the fact that efficiency scores are not observed directly but rather are "estimated" from the DEA output. First, the dependent variables may be serially correlated. While maximum likelihood estimation of equation (2) will provide consistent results, the correlation can lead to invalid inference unless some form of bootstrapping is employed. Second, by virtue of the minimum bound of zero on the constructed $\alpha_{j}^{k}$ there is a condition on each $e_{j}^{k}$; namely, they are lower bounded by $-\mathrm{f}_{\mathrm{j}}\left(\mathrm{z}_{\mathrm{j}}^{\mathrm{k}}, \beta_{\mathrm{j}}\right)$. This must be taken into account in the bootstrapping. Third, observations of efficient firms (whose TE is 1 or whose slacks are 0 ) create a probability mass at one or other of these bounded values. Simar and Wilson (2007) argue that such a finding arises through the use of a finite sample employed to obtain the relative efficiency values and the use of a (left) truncated regression rather than a Tobit as being better suited to the circumstances. 
Since we have an interest in whether exogenous factors inhibit (or enable) water agencies from being relatively more efficient than their peers, it is important that we are able to undertake valid hypothesis testing. Thus, in addition to estimating a traditional Tobit, we adopt the bootstrapping truncated regression algorithm described in Simar and Wilson (2007).

Independent of the approach taken in the second stage, the third stage of our analysis involves running the DEA procedure again with the original $y^{\mathrm{k}}$ and a set of adjusted input measures $x_{j}^{k-a d j}$ defined in equation (3)

(3) $x_{j}^{k-a d j}=x_{j}^{k}+\left[\max _{k}\left(z_{k} \beta_{j}\right)-z_{k} \beta_{j}\right]$

The ${ }^{\wedge}$ denotes the predicted value of $\beta_{\mathrm{j}}{ }^{\mathrm{k}}$ from either the Tobit or the bootstrapped truncated regressions. The purpose of the adjustment is to establish a base equal to the least favourable external conditions. That is, an agency with external conditions corresponding to this base will not have its inputs adjusted at all. Conversely, an agency with a more favourable set of external conditions will have its input quantities adjusted upward to make it comparable to less-well situated agencies. Carrying out this adjustment removes the differences in external operating environments that may confound efforts to assess agencies' relative technical efficiency. 
The data are from a cross-sectional sample of sixty-four municipal water supply agencies operating in Ontario, Canada during 1996. The first stage DEA employs observations on the municipal water agencies' outputs and inputs. Output is measured as the sum of annual deliveries $\left(1,000 \mathrm{~m}^{3} / \mathrm{yr}\right)$ to residential, commercial, industrial and "other" customer categories. These observations are available in Environment Canada's Municipal Water Use Database (Environment Canada, 1999). Inputs used in the DEA are labour expenditures, materials expenditures and kilometers of distribution network. The expenditure data are available in the municipal governments' annual financial reports to the Ontario provincial government (Government of Ontario, 2001). The data regarding the length of systems' distribution networks are taken from Ontario Water Works Association (1997).

The second stage regression analysis uses total input slack values from the first stage as the dependent variable (defined in equation 1) and observations on exogenous environmental factors as right-hand side regressors. The explanatory variables are the same across equations but, by estimating separate equations for each input slack, their respective influences are allowed to differ across inputs in each estimation model. The first environmental variable measures the difference in elevation between each city's highest point and its water treatment facility (National Topographic Data Base, 2001). The second measures each city's population density (Statistics Canada, 1998). The third measures the ratio of residential water use to total water agency output (Environment Canada, 1999). The fourth measures the number of private dwellings in each city in 1996 (Statistics Canada, 1998). The fifth measures the maximum weekly summer temperature 
observed in 1996 for each city (Environment Canada, 2004). The final variable measures the total precipitation in each city (Environment Canada, 2004).

These variables have three features in common. First, they vary from city to city. Second, they can be expected to influence the nature of the operations of the local water supplier. These variables, however, are not expected to have the same influence on output, costs or input use. The first three variables reflect features that are expected to influence the cost of supply while the remaining variables are expected to influence demand for potable water. For example, the greater the changes in temperature, all of things being equal, the higher the capital and operating costs for a water supplier. Similarly, the greater the average maximum summer weekly temperature, then the higher the expected demand for water. Third, these variables are outside of the control of local water agency managers. Descriptive statistics and definitions for all of the variables are set out in tables 1 and 2 .

\section{RESULTS}

Table 3 reports several statistics related to the first and third stage DEA procedures. The third stage DEA results will be discussed below. In the first stage, the average level of technical efficiency is quite low (0.538) and there is considerable dispersion of TE scores. Only 9 of the 64 water suppliers achieve a TE score of 1 . Furthermore, there are positive nonradial slacks for all of the inputs. 
The second stage Tobit model performs relatively well as reported in Table 4. Higher levels of summer temperatures contribute to higher input slacks for labour and materials. On the other hand, a greater difference between the elevation of the water utility and the highest elevation in a region, a greater number of dwellings in a region, and a higher ratio of residential water use to total output each contribute to a reduction in labour and materials slacks. Higher precipitation in the summer months is the only environmental factor that increases distribution slacks significantly. Results from the bootstrapped truncation regression are similar to those of the Tobit, although a greater number of environmental factors have coefficients that are significant. Larger amounts of precipitation over the year contribute positively to all three input slacks. Water agencies whose source water is surface also have significantly greater labour slacks than do water agencies that use groundwater. ${ }^{\text {iv }}$ Population density increases slacks for both labour and materials, as do the number of dwellings.

We use the coefficients from Tables 4 and 5 in order to carry out the two sets of input adjustments (one using the Tobit estimates and the other using the bootstrapped truncated regression estimates) needed for the third stage as set out in equation (3). Table 3 also reports several statistics related to the third stage DEA. It is clear that adjusting the input quantities to account for differences in the water agencies' exogenous operating environments has a significant impact on the efficiency scores. First, the mean TE score increases to 0.604 for the Tobit adjustment and even higher to 0.822 using the truncated regression adjustment. More importantly, the minimum TE score almost doubles in the Tobit case and triples in the truncated regression case. Second, the dispersion of TE 
scores decreases in both cases. In addition, two of the three nonradial input slacks decrease in the Tobit case (one in the truncated regression case). The TE scores before and after the second stage Tobit adjustment exhibit a Pearson correlation coefficient of 0.45 , while the correlation between the first stage TE and third stage truncated regression TE is 0.29 . Finally, the correlation between the two sets of adjusted TE scores (Tobit and truncated regression) is 0.52. In general, these results parallel Fried al (1999) who also found that adjusting for external factors led to higher average TE scores and reduced dispersion in individual agencies' TE scores.

\section{CONCLUSIONS}

There is a growing interest in understanding and assessing the performance of local water supply agencies and there is a need to develop analytic techniques that can do this. We have presented a multistage procedure that combines DEA and regression analysis to measure and assess the relative technical efficiency of municipal water suppliers. The strength of this approach is that it not only tests for the influence of exogenous environmental factors on the relative efficiency rankings but also calculates the relative efficiency rankings with these exogenous effects filtered out. As a result, what remains is a technical efficiency score that reflects differences in features internal to the agency rather than external factors outside of managerial control. For this sample of water agencies, the main finding is that taking exogenous environmental influences into account has a significant impact on measured input slacks and efficiency scores and that 
the agencies are, on average, more efficient (or less inefficient) than an unadjusted DEA procedure suggests. 


\section{REFERENCES}

Anwandter L. and T. Ozuna (2002) "Can public sector reforms improve the efficiency of public water utilities?" Environment and Development Economics 7: 687-700

Byrnes, P., S. Grosskopf and K. Hayes (1986) "Efficiency and Ownership: Further Evidence" Review of Economics and Statistics 65 (May): 337-341.

Charnes, A., W.W. Cooper and E. Rhodes (1978) "Measuring the Efficiency of Decision Making Units" European Journal of Operational Research 2(6): 429-444.

Coelli, T., D.S.P. Rao and G. Battese (1999) An Introduction to Efficiency and Productivity Analysis Boston: Kluwer Academic Publishers.

Conti, M. (2005) "Ownership Relative Efficiency in the Water Industry: A Survey of the International Empirical Evidence" Economics Internazionale 58(3): 273-306.

De Witte, K. and R. Marques (2008) "Capturing the environment, a metafrontier approach to the drinking water sector" Center for Economic Studies Discussion Paper 0804, Catholic University of Louvain.

Environment Canada (2004) "Climate Data Online"

http://www.climate.weatheroffice.ec.gc.ca/climateData/canada_e.html website accessed June, 2004.

Environment Canada (1999) "Municipal Water Use Database" document downloaded from website http://www.ec.gc.ca/water/en/manage/use/e data.htm June 20, 2003.

Fried, H.O., S.S. Schmidt and S. Yaisawarng (1999) "Incorporating the Operating Environment into a Nonparametric Measure of Technical Efficiency" Journal of Productivity Analysis 12(3): 249-267.

Government of Ontario (2001) Municipal Performance Measurement Program Ontario Ministry of Municipal Affairs and Housing, Toronto.

Lambert, D., D. Dichev and K. Raffiee (1993) "Ownership and sources of inefficiency in provision of water services" Water Resources Research 29: 1573-1578.

Madhoo, Y. (2007) "International Trends in Water Utility Regimes" Annals of Public and Cooperative Economics 78(1): 87-135.

National Topographic Data Base [computer file]. (2001) Ottawa, Ontario: Natural Resources Canada, Geomatics Canada 
Ontario Water Works Association (1997) "Municipal Water Rates \& Operations Benchmarking (1996 data)", Markham, Ontario.

Renzetti, S. (1999) "Municipal Water Supply and Sewage Treatment: Costs, Prices and Distortions" Canadian Journal of Economics, 32(2): 688-704.

Renzetti, S. (2007) "Are the Prices Right? Balancing Efficiency, Equity, and Sustainability in Water Pricing" in K. Bakker, ed. Eau Canada: The Future of Canada's Water, Vancouver: UBC Press, pp. 263-279.

Renzetti, S. and D. Dupont (2003) "Ownership and Performance of Water Utilities" Greener Management International, 42: 9-19.

Shih, J-S., W. Harrington, W. Pizer and K. Gillingham (2004) "Economies of Scale and Technical Efficiency in Community Water Systems" Discussion Paper 04-15, Resources for the Future, Washington, D.C.

Shirley, M. (2002) ed. Thirsting for Efficiency: The Economics and Politics of Urban Water System Reform, Elsevier Publishing

Simar, L. and P. Wilson (2007) "Estimation and inference in two-stage, semi-parametric models of production processes" Journal of Econometrics 136: 31-64.

Statistics Canada (1998) The Nation: 1996 Census of Population, Ottawa.

Thanassoulis, E. (2001) Introduction to the Theory and Application of Data Envelopment Analysis, Norwell: Kluwer Academic Publishers

Water Strategy Expert Panel (2005) Watertight: the case for change in Ontario's water and wastewater sector, report prepared for the Ontario Ministry of Public Infrastructure Renewal http://www.waterpanel.ontario.ca/ 
Figure 1: Efficiency Measurement and Input Slacks

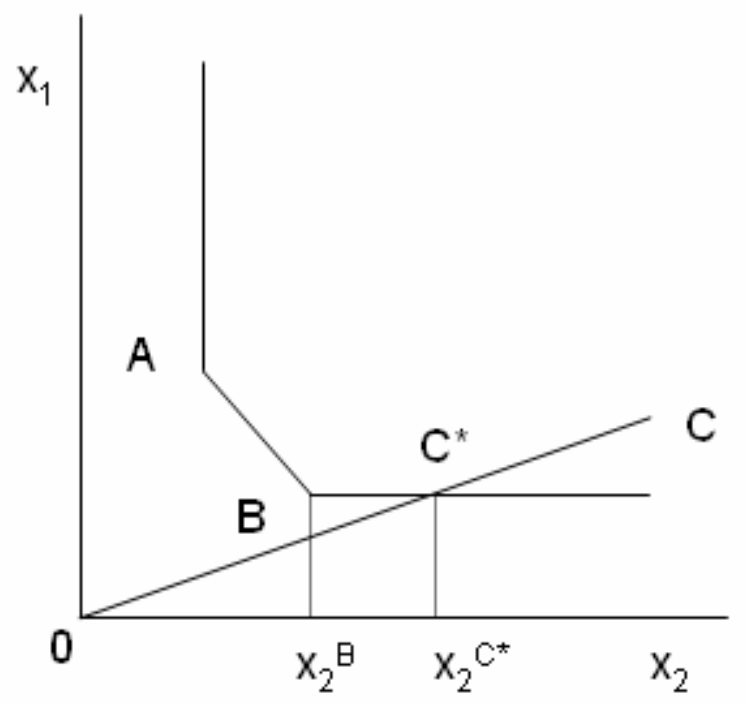

Figure 1 
Table 1: Descriptive Statistics

\begin{tabular}{|c|c|c|c|c|}
\hline & Mean & $\begin{array}{l}\text { Standard } \\
\text { Deviation }\end{array}$ & Minimum & Maximum \\
\hline \multicolumn{5}{|l|}{ Outputs: } \\
\hline Totq & $10854.62^{1}$ & 27256.46 & 128.85 & 152406.85 \\
\hline \multicolumn{5}{|l|}{ Inputs: } \\
\hline Materials & 956.78 & 1554.51 & 23.32 & 9955.35 \\
\hline Labour & 1053.15 & 2039.08 & 10.95 & 9589.95 \\
\hline Distribution length & 254.75 & 396.48 & 9.00 & 1751.00 \\
\hline \multicolumn{5}{|l|}{ Explanatory: } \\
\hline XTEMP & 30.09 & 1.13 & 27.73 & 33.16 \\
\hline PRECIP & 1072.90 & 101.81 & 804.30 & 1355.47 \\
\hline SOURCE & 0.73 & 0.45 & 0.00 & 1.00 \\
\hline POPDEN & 884.14 & 963.16 & 13.20 & 6633.20 \\
\hline ELEV & 53.17 & 66.00 & 0.00 & 325.00 \\
\hline RATIO & 56.55 & 18.92 & 22.00 & 96.04 \\
\hline DWELL & 21572.41 & 49692.36 & 471.00 & 289178.00 \\
\hline $\mathbf{N}=64$ & & & & \\
\hline
\end{tabular}

Table 2: Variable Definitions

\begin{tabular}{|c|c|c|}
\hline Variable & Units & Description \\
\hline \multicolumn{3}{|l|}{ Outputs: } \\
\hline Totq & $1000 \mathrm{~m}^{3} /$ year & output \\
\hline \multicolumn{3}{|l|}{ Inputs: } \\
\hline Materials & 1996 Can\$/year & $\begin{array}{l}\text { Expenditures on materials and energy } \\
\text { inputs }\end{array}$ \\
\hline Labour & 1996 Can\$/year & Expenditures on labour input \\
\hline Distribution Length & Kilometres & $\begin{array}{l}\text { distance between water utility and } \\
\text { highest elevation in meters }\end{array}$ \\
\hline \multicolumn{3}{|l|}{ Explanatory: } \\
\hline XTEMP & Degrees Celsius & $\begin{array}{l}\text { Extreme temperature over June, July } \\
\text { and August }\end{array}$ \\
\hline PRECIP & Millimetres & Total annual precipitation \\
\hline SOURCE & & $1=$ surface, $0=$ groundwater \\
\hline POPDEN & & Population per $\mathrm{km}^{2}$ \\
\hline ELEV & metres & $\begin{array}{l}\text { Distance between water utility and } \\
\text { highest elevation }\end{array}$ \\
\hline RATIO & & $\begin{array}{l}\text { Residential demand as percent of total } \\
\text { demand }\end{array}$ \\
\hline DWELL & & Number of dwellings in 1996 \\
\hline
\end{tabular}


Table 3: Statistics on Technical Efficiency Scores

\begin{tabular}{|l|l|l|l|}
\hline Statistic & $\begin{array}{l}\text { Stage 1 } \\
\text { (before adjustment) }\end{array}$ & $\begin{array}{l}\text { Stage 3 } \\
\text { (after Tobit } \\
\text { adjustment) }\end{array}$ & $\begin{array}{l}\text { Stage 3 } \\
\text { (after } \\
\text { bootstrapped } \\
\text { truncated } \\
\text { regression } \\
\text { adjustment) }\end{array}$ \\
\hline & & & \\
\hline $\begin{array}{l}\text { Technical } \\
\text { Efficiency }\end{array}$ & & & 0.822 \\
\hline Mean TE & 0.538 & 0.604 & 1.0 \\
\hline Max TE & 1.0 & 1.0 & 0.560 \\
\hline Min TE & 0.150 & 0.283 & 0.127 \\
\hline $\begin{array}{l}\text { Standard Deviation } \\
\text { (TE) }\end{array}$ & 0.256 & 0.191 & 8 \\
\hline \# obs. with TE=1 & 9 & 7 & \\
\hline & & & $9.85 \%$ \\
\hline $\begin{array}{l}\text { Nonradial Input } \\
\text { Slacks }\end{array}$ & & & $1.56 \%$ \\
\hline Labour & $7.51 \%$ & $13.62 \%$ & $50.70 \%$ \\
\hline Materials & $7.35 \%$ & $1.5 \%$ & \\
\hline $\begin{array}{l}\text { Distribution } \\
\text { Network }\end{array}$ & $5.98 \%$ & $4.55 \%$ & \\
\hline
\end{tabular}

Notes to Table 3

1. Each input slack is measured relative to that input's mean quantity.

2. The Pearson R-squared correlation between TE scores (before and after adjustment) is 0.467 (significant at the 0.01 level) have not done this 
Table 4: Stage 2 - Tobit Estimation

\begin{tabular}{|l|c|c|c|}
\hline Variable/Input & Labour & Materials & Distribution \\
\hline XTEMP & $197.99^{* *}$ & $210.55^{* *}$ & -9.66 \\
\hline & $(99.72)$ & $(65.13)$ & $(30.76)$ \\
\hline PRECIP & -0.83 & -0.75 & $0.44^{*}$ \\
\hline & $(1.04)$ & $(0.68)$ & $(0.33)$ \\
\hline SOURCE & 15.20 & -250.71 & 83.23 \\
\hline & $(243.85)$ & $(159.51)$ & $(75.06)$ \\
\hline POPDEN & 0.15 & 0.15 & 0.01 \\
\hline ELEV & $(0.24)$ & $(0.15)$ & $(0.08)$ \\
\hline & $-3.57^{* *}$ & $-2.56^{* *}$ & -0.76 \\
\hline RATIO & $(1.81)$ & $(1.19)$ & $(0.57)$ \\
\hline & $-14.40^{* *}$ & $-14.83^{* * *}$ & -0.83 \\
\hline DWELL & $(6.02)$ & $(3.94)$ & $(1.87)$ \\
\hline & $-0.01^{* *}$ & $-0.01^{* *}$ & -0.002 \\
\hline CONSTANT & $(0.00)$ & $(0.00)$ & $(0.00)$ \\
\hline & -4073.93 & $-4229.27^{*}$ & -137.75 \\
\hline & $(3486.34)$ & $(2272.25)$ & $(1081.93)$ \\
\hline & & & \\
\hline SIGMA & & & $232.28^{* * *}$ \\
\hline & $751.80^{* * *}$ & $491.15^{* * *}$ & $(22.54)$ \\
\hline & $(73.35)$ & $(47.96)$ & \\
\hline
\end{tabular}

Note: * Coefficient is significant at $10 \%$

** Coefficient is significant at $5 \%$

$* * *$ Coefficient is significant at $1 \%$ 
Table 5: Stage 2 - Bootstrapped Truncated Regression Results

\begin{tabular}{|c|c|c|c|}
\hline Variable/Input & Labour & Materials & Distribution \\
\hline \multirow[t]{2}{*}{ XTEMP } & $255.70 * *$ & $370.27 * * *$ & $181.21 * * *$ \\
\hline & $(84.16)$ & $(105.77)$ & $(240.68)$ \\
\hline \multirow[t]{2}{*}{ PRECIP } & $3.64 * *$ & $2.43 * *$ & $1.20 * *$ \\
\hline & $(0.91)$ & $(0.94)$ & $(2.11)$ \\
\hline \multirow[t]{2}{*}{ SOURCE } & $1148.15 * * *$ & 215.42 & na \\
\hline & (195.39) & $(177.51)$ & na \\
\hline \multirow[t]{2}{*}{ POPDEN } & $1.03 * * *$ & $0.90 * * *$ & 0.02 \\
\hline & $(0.20)$ & $(0.28)$ & $(0.23)$ \\
\hline \multirow[t]{2}{*}{ ELEV } & $-3.10 * * *$ & -2.94 & 0.72 \\
\hline & $(1.55)$ & $(1.87)$ & $(1.87)$ \\
\hline \multirow[t]{2}{*}{ RATIO } & $-22.43 * * *$ & $-22.55 * * *$ & 2.03 \\
\hline & $(6.18)$ & $(6.96)$ & $(4.30)$ \\
\hline \multirow[t]{2}{*}{ DWELL } & $0.04 * * *$ & $0.02 * * *$ & 0.01 \\
\hline & $(0.002)$ & $(0.004)$ & $(0.01)$ \\
\hline \multirow[t]{2}{*}{ CONSTANT } & $-12587.40 * *$ & $-13491.90 * * *$ & $-6758.87 * * *$ \\
\hline & $(3025.58)$ & $(4185.28)$ & $(5609.54)$ \\
\hline \multirow[t]{2}{*}{ SIGMA } & $41.78 * * *$ & $62.18 * * *$ & $18.81 * * *$ \\
\hline & 105.54 & $(119.08)$ & $(55.41)$ \\
\hline
\end{tabular}

Note:

- * Coefficient significant at 10\% level

- ** Coefficient significant at $5 \%$ level

- $\quad * * *$ Coefficient significant at $1 \%$ level

\footnotetext{
${ }^{\mathrm{i}}$ Renzetti is the contact author. Department of Economics, Brock University, St. Catharines, Ontario, Canada L2S 3A1, Phone: (905) 688-5550, steven.renzetti@brocku.ca. The authors thank the Donner Canadian Foundation for financial support, Megan Ihrig and Victoria Tasker for their assistance with the data and an anonymous reviewer for constructive comments. All errors and omissions are the responsibility of the authors.

${ }^{i i}$ Department. of Economics, Brock University, St. Catharines, Ontario, Canada

iii De Witte and Marques (2008) consider a slightly different extension of Fried et al in which observations may be grouped (e.g. by political jurisdiction or climatic zone) and a multistage, metafrontier procedure allows each agency to be compared both to agencies within its group as well as to agencies in other groups. ${ }^{\text {iv }}$ A model that included the surface water dummy variable did not converge for the case of distribution slacks when doing the truncated regression. This may be attributable to insufficient variation in this explanatory variable in the context of the types of distribution networks in our data set.
} 